\title{
Study of adequacy of informed consent in caesarean section in a tertiary care, teaching and research institute of Northern India
}

\section{Latika*, Smiti Nanda, Nirmala Duhan, Roopa Malik}

Department of Obstetrics \& Gynecology, PT.B.D.S.PGIMS, Rohtak, Haryana, India

Received: 09 April 2015

Accepted: 18 April 2015

*Correspondence:

Dr. Latika,

E-mail: latika.duhan@gmail.com

Copyright: () the author(s), publisher and licensee Medip Academy. This is an open-access article distributed under the terms of the Creative Commons Attribution Non-Commercial License, which permits unrestricted non-commercial use, distribution, and reproduction in any medium, provided the original work is properly cited.

\section{ABSTRACT}

Background: Informed consent consists of availing information to the patient in an understandable manner without coercion to allow the patient to make an informed decision about their healthcare. In the case of caesarean section, information must include name, nature, proposed benefits of the procedure, risks of the procedure, alternative procedures, implications on the future reproductive health and anesthetic options. Aim and objective: To study the adequacy of informed consent in patients who undergo caesarean section at PT. B. D. Sharma, PGIMS, Rohtak.

Methods: It was a cross sectional study. The study population was the group of patients who underwent emergency or elective caesarean section at PGIMS, Rohtak. A pretested questionnaire was adopted from a study carried out at School of Medicine, University of Zambia and was administered to the patients.

Results: It was found that majority of the patients were in the age group of 21-30 years and most of them (71\%) were from the rural areas. In $90 \%$ of the cases the outcome of caesarean section was term live births and majority of them $(84 \%)$ were emergency caesarean section. The patients were asked fourteen questions regarding various aspects of informed consent based on the five point Likert scale.

Conclusions: Majority of the caesarean sections were performed due to some emergency indications. It was found that overall patients were well informed about the procedure and the related consequences.

Keywords: Caesarean section, Informed consent

\section{INTRODUCTION}

Informed consent consists of availing information to the patient in an understandable manner without coercion to allow the patient to make an informed decision about their healthcare. Worldwide, caesarean section is one of the commonest operations to be performed by the obstetrician. ${ }^{1}$ Decision of performing a caesarean section must be followed by a legitimate informed consent from the patient or her guardian..$^{2-10}$ In the case of caesarean section, information must include name, nature, proposed benefits of the procedure, risks of the procedure, alternative procedures, implications on the future reproductive health and anesthetic options. Informed consent is both an ethical and legal requirement. In early times, all patients who had undergone caesarean section were subjected to elective caesarean section for their subsequent deliveries. ${ }^{11,12}$ However in current set-up the situation has changed and vaginal birth after caesarean section has become an acceptable alternative. This is also referred as trial of labour or trial of scar. ${ }^{8,11-14}$ The World Health Organization has projected a target that caesarean section rate should be up to $15 \% .{ }^{15}$ In today's times rate of caesarean section has increased many times due to various reasons. The decision of caesarean section depends on availability of many crucial factors like presence of trained surgeon, availability of blood transfusion facilities and safe anesthesia facilities. ${ }^{16,17}$ It is well implicit that informed consent is required for all patients posted for an elective or emergency caesarean 
section. However, it is not clear that to what extent the current consenting practice at our institute offers them an opportunity to make an informed judgment.

Therefore, a study was planned at the department of Obstetrics \& Gynecology, PT. B. D. Sharma, PGIMS, Rohtak for studying and assessing the understanding of information obtained by patients undergoing caesarean section and their involvement in the consenting process and hence was aimed at providing insight into the sufficiency of consenting process for caesarean sections.

\section{Aim \& objectives}

Aim

1. To study the adequacy of informed consent in caesarean section at PT. B. D. Sharma, PGIMS, Rohtak

\section{Objectives}

1. To assess proportion of patients receiving adequate informed consent before caesarean section.

2. To determine the basics of informed consent provided for the caesarean section.

\section{METHODS}

The study was carried out in the department of Obstetrics and Gynecology of Pt. B. D. Sharma, PGIMS, Rohtak. This was a cross sectional study and the study population was picked up from the patients who underwent elective and emergency caesarean section. The eligibility criterion was prepared for selecting patients in the study group. The patients who were more than 18 years of age and underwent an elective/emergency caesarean section at PGIMS, Rohtak and had given consent for participation in the study were included in the study and on the other hand, patients less than 18 years and who underwent caesarean section at other hospital and who refuse to participate in the study were excluded from the study. The convenient sampling technique was used and total fifty six (56) participants were selected.

The procedure planned for and performed before labour, or any complications arose, was defined as elective caesarean section and the surgery which was unplanned for and was performed during labour or after complications arose, was defined as emergency caesarean section.

The study tool, a pretested questionnaire of some other study ${ }^{18}$ was adopted and modified to some extent as per the local needs of the study. The questionnaire contained two parts. Part-I contained questions regarding socio demographic profile of the participant and other obstetrics details were obtained from their case files. This section had total ten questions. Part II contained statements regarding the procedure performed/anesthesia administered and various aspects of informed consent. Each statement carried five options and the patients needed to choose one of the option. This part of questionnaire carried fourteen statements.

\section{Statistical analysis}

The data was entered into the Microsoft excel sheet and the data base was created. The data was analyzed by the SPSS software. Part-II of questionnaire carried 14 different statements and each had five options based on the Likert scale. The adequacy of informed consent was assessed on the basis of reply (i.e. strongly agree/agree) of these statements i.e. name of the procedure, nature of the procedure and indications of the procedure. The Chi square test was used and $\mathrm{p}$ valve was calculated.

\section{Ethical clearance}

This study does not deal with the ethical issues. This study does not have any human/animal experimentation. This is a questionnaire based study and the opinions of participants were elicited through questionnaire.

\section{RESULTS}

\section{Demographic distribution of the participants}

It was found that majority (79\%) of the participants were in the 21-30 years age group. Ninety five percent of the participants were married and majority of them were from the rural areas. The educational status of the participants was analyzed and it was found that most of them were educated up to middle standard (25\%) followed by participants who had studied up to matriculation $(21 \%)$. Majority of the participants had term live birth $(91 \%)$ and eighty four $(84 \%)$ of the participants were posted for emergency caesarean section (Table 1).

\section{Analysis of different statements of participants}

The part II of the questionnaire consisted of 14 different statements for eliciting the response of the participants. The response of the participants was distributed in two different categories i.e. adequate or not adequate. The bivariate analysis was done by applying chi square test on these two categories. The knowledge of participants was adequate regarding few aspects of informed consent e.g. name of operation, nature of operation and indication of procedure etc. and the difference was statistically highly significant $(\mathrm{P}<0.001)$. On the other hand, the knowledge of participants was not adequate regarding few other aspects of the informed consent e.g. option of anesthesia, debriefing regarding procedure and right to refuse or defer the procedure etc. and their difference was also statistically significant $(\mathrm{P}<0.001)$ (Table 2$)$. 
Table 1: Demographic distribution of the participants.

\begin{tabular}{|ll|}
\hline Age (years) & Number of participants \\
\hline $18-20$ & $7(12.5 \%)$ \\
\hline $21-30$ & $44(78.5 \%)$ \\
\hline $31-40$ & $3(5.3 \%)$ \\
\hline Information not available & $2(3.5 \%)$ \\
\hline Marital status & $3(5.4 \%)$ \\
\hline Single & $53(94.6 \%)$ \\
\hline Married & \\
\hline Place of residence & $41(73.2 \%)$ \\
\hline Rural & $15(26.8 \%)$ \\
\hline Urban & \\
\hline Education Level & $14(25 \%)$ \\
\hline Up to Middle & $12(21.4 \%)$ \\
\hline Up to Matric & $4(7 \%)$ \\
\hline Up to 10+2 & $11(19.6 \%)$ \\
\hline Up to Graduation & $3(5.3 \%)$ \\
\hline Up to Post graduation & $5(8.9 \%)$ \\
\hline Iliterate & $7(12.5 \%)$ \\
\hline Information not available & \\
\hline Number of days since C. section & $25(44.6 \%)$ \\
\hline 0-3 days & $13(23 \%)$ \\
\hline 4-6 days & $6(10.7 \%)$ \\
\hline Above 6 days & $12(21.4 \%)$ \\
\hline Information not available & $51(91 \%)$ \\
\hline Outcome of procedure & $4(7 \%)$ \\
\hline Term live birth & $1(2 \%)$ \\
\hline Preterm live birth & \\
\hline Still birth & \\
\hline Type of procedure & \\
\hline Elective & \\
\hline Emergency & \\
\hline Not clear & \\
\hline
\end{tabular}

Table 2: Analysis of responses of the participants.

\begin{tabular}{|c|c|c|c|}
\hline Parameter & Adequate & Not adequate & P value \\
\hline Told the name of operation & $52(92.8 \%)$ & $4(7.14 \%)$ & $\mathrm{P}<0.001$ \\
\hline Told about that cut on the abdomen and the baby delivered through the abdomen? & $55(98.21 \%)$ & $1(1.78 \%)$ & $\mathrm{P}<0.001$ \\
\hline Told why a caesarean was necessary & $48(85.71 \%)$ & $8(14.28 \%)$ & $\mathrm{P}<0.001$ \\
\hline $\begin{array}{l}\text { If answer to Q (13) is a) or b) what were you told? (patient own words) } \\
\text { Corresponds with indication in Part } 1 \text { (Q9) (as judged by the interviewer) }\end{array}$ & $42(75 \%)$ & $14(25 \%)$ & $\mathrm{P}<0.05$ \\
\hline Understand the reason why a caesarean was necessary? & $49(87.5 \%)$ & $7(12.5 \%)$ & $\mathrm{P}<0.001$ \\
\hline Agreed that a caesarean was necessary & $48(85.71 \%)$ & $8(14.28 \%)$ & $\mathrm{P}<0.001$ \\
\hline Told that a caesarean section has risks of its own & $18(32.14 \%)$ & $38(67.86 \%)$ & $\mathrm{P}>0.05$ \\
\hline Given a chance to ask questions about the intended caesarean section & $15(26.78 \%)$ & $41(73.21 \%)$ & $\mathrm{P}<0.05$ \\
\hline Told that had the right to refuse or defer the caesarean Section decision? & $25(44.64 \%)$ & $31(55.36 \%)$ & $\mathrm{P}>0.05$ \\
\hline Told about the options of general or regional anesthesia & $11(19.64 \%)$ & $45(80.36 \%)$ & $\mathrm{P}<0.05$ \\
\hline Allowed to choose your anesthetic preference & $7(12.5 \%)$ & $49(87.5 \%)$ & $\mathrm{P}<0.001$ \\
\hline Advised on your delivery options for future pregnancies & $18(32.14 \%)$ & $38(67.86 \%)$ & $\mathrm{P}<0.05$ \\
\hline After the caesarean section a health care provider debriefed the operation & $4(7.14 \%)$ & $52(92.8 \%)$ & $\mathrm{P}<0.001$ \\
\hline During antenatal visit, you were told about possibility of delivery by & $21(37.5 \%)$ & $35(62.5 \%)$ & $\mathrm{P}>0.05$ \\
\hline
\end{tabular}




\section{DISCUSSION}

Obstetric patients present multiple ethical challenges to the healthcare provider at the time of informed consent regarding disclosure of information. A cross sectional study was carried out to assess the adequacy of informed consent at our institute based on responses given by participants to the questions asked, it was found that most of the participants belonged to 21-30 years age group (78.5\%), were married $(94.6 \%)$ and belonged to rural background $(73.2 \%)$. Most of them $(25 \%)$ had studied till middle standard followed by those $(21.4 \%)$ who had read till matric standard. Forty five percent of patients were those who had their postoperative day 0 to postoperative day 3 of hospital stay, followed by $23 \%$ having history of LSCS 4-6 days back and eleven percent revealed history of LSCS greater than 6 days back. Majority (91\%) of patients had given birth to term live babies, followed by $7 \%$ patients who had preterm live birth and $2 \%$ patients having stillbirth as outcome of their surgeries. Most of the patients $(84 \%)$ had emergency LSCS, followed by patients who had elective LSCS. The part II of the questionnaire contained fourteen questions and response of patients was measured in the form of Likert scale based options. If the patient gave answer as strongly agree/agree than the response was considered as adequate, and in other options, it was considered as an inadequate response.

Majority of the patients $(93 \%)$ were adequately informed about the name of the procedure, and the difference was statistically highly significant $(\mathrm{P}$ value $<0.001)$. Ninety eight percent patients had adequate knowledge about the nature of the operation and eighty five percent patients had adequate knowledge of indication of the procedure. The difference was statistically significant in both the aspects ( $\mathrm{P}$ value being $<0.001$ ). Out of total patients who knew indication of caesarean section, $75 \%$ of them told the indication correctly which corresponded with their case notes, in $25 \%$ of the cases, indication told by patients didn't match with case notes ( $\mathrm{P}$ value $<0.05)$. On the other hand patients were not adequately informed about the risks of caesarean section as sixty eight percent had denied having been told the risks of surgery and majority of the patients $(73 \%)$ were not given the chance to ask queries regarding their surgery. The difference was statistically significant in both the cases ( $\mathrm{P}$ value $<0.05)$. It was found that majority of the patients $(80 \% \& 87 \%$ respectively) were not adequately informed about the type of anesthesia and were not given the chance to choose their anesthetic preference ( $\mathrm{P}$ value $<0.05$ ). Out of total participants included in study, 32.14\% agreed having been told preferences for future pregnancies while $67.86 \%$ disagreed to the same ( $\mathrm{P}$ value $<0.05)$. In a study carried out at Nigeria (2008) on surgical procedures (including obstetric procedures) it was concluded that only $26.3 \%$ of patients knew any alternative to the procedure, $36.3 \% \mathrm{knew}$ at least one complication of the procedure and $15 \%$ knew an option or complication of anesthesia.
In our current study ninety three percent patients refused having been adequately debriefed by healthcare provider after surgery ( $\mathrm{P}$ value $<0.001)$. Antenatal visit is the appropriate time to sensitize a patient about possibility of caesarean section in certain conditions in future. $37.5 \%$ agreed to the fact that they were told that they might need surgery in future during their antenatal visit, while $62.5 \%$ refused having been told so ( $\mathrm{P}$ value $>0.05$ ). Overall most of the case files showed good documentation however consenting process can be made better by following a proper proforma/checklist which should contain all the essential elements to be covered in consent. Adisa et al. also recommend a well-structured and standardized method of obtaining informed consent from surgical patients. Ezeome and Marshall reporting on informed consent in Nigeria (2009) made recognition of individual autonomy but also that decisions were made within the family.

\section{CONCLUSION}

Majority of the caesarean sections were performed due to some emergency indications. It was found that overall patients were well informed about the procedure and the related consequences; however few elements were not covered in the consent. Thus, it can be concluded that process of informed consent can be improved by forming proper proforma/checklist and training of the healthcare professionals who are involved in consenting process.

\section{ACKNOWLEDGMENTS}

The questionnaire used in our study was adopted from the study carried out by Dr. David C. Lubansa MB. ChB. (UNZA). A study of adequacy of informed consent for caesarean section at the university teaching Hospital, Lusaka, Zambia, The University of Zambia, School of Medicine: 2010.

\section{Funding: No funding sources \\ Conflict of interest: None declared \\ Ethical approval: Not required}

\section{REFERENCES}

1. Walker R, Turnbull D, Wilkinson C. Strategies to address global caesarean section rates. A review of evidence. Birth. 2002;29(1):28-39.

2. Royal College of Obstetricians and Gynecologists. Caesarean section. In: RCOG, eds. Consent Advice 7. 2nd ed. UK: RCOG; October 2009.

3. Childbirth Connection. What every woman needs to know about caesarean section. In: CC, eds. A Report. 2nd ed. New York: Childbirth Connection; December 2006.

4. Child Birth Connection. Informed decision making, informed consent or refusal, 2013. Available at: http://www.childbirthconnection.org/article.asp?ck= 10081\#rights. 
5. Queensland Health Obstetrics \& Gynecology 03 Version 4. Caesarean section procedural consent form, November 2006. Available at: http://www.health.qld.gov.au/consent/documents/obs t_gyna_04.pdf.

6. Carmi A. The UNESCO Chair in Bioethics, Israel National Commission for UNESCO. Informed consent, 2003. Available at: http://unesdoc.unesco.org/images/0014/001487/1487 13e.pdf.

7. Haire D. Alliance for the Improvement of Maternity Services (AIMS). The pregnant patients' bill of rights, 2000. Available at: http://www.aimsusa.org/ppbr.htm. Accessed 25 May 2006.

8. National Institute of Clinical Excellence (NICE). NHS guidelines on caesarian section. In: NICE, eds. A Guideline. London (UK): NICE; April 2004: 142.

9. Turnbull DA, Wilkinson C, Yaser A, Carty V, Svigos JM, Robinson JS. Women's role and satisfaction in the decision to have a caesarean section. Med J Aust. 1999 Jun;170(12):580-3.

10. ACOG. Informed consent. In: ACOG, eds. Ethics in Obsterics and Gyanecology. Washington, DC: American College of Obstetrician and Gyanecologists; 2004.

11. Roberts LJ. Elective section after two sectionswhere's the evidence. Br J Obstet Gynaecol. 1991 Dec;98(12):1192-202.

12. Flamm BL. Vaginal Birth after caesarean (VBAC). Best Pract Res Clin Obstet Gynaecol. 2001 Feb;15(1):81-92.
13. Society of Obstetrician and Gynaecologists of Cananda (SOGC). Guidelines for vaginal birth after previous caesarian birth. J Obstet Gynaecol Can. 2005;27(2):164-74.

14. RCOG. The national sentinel caesarean section audit report. In: RCOG, eds. RCOG Clinical Effectiveness Support Unit. UK: Royal College of Obstetrician and Gynaecologists; 2001: 45.

15. World Health Organization. Appropriate technology for birth. Lancet. 1985;326(8452):436-7.

16. Lawson BL, Harrison KA, Bergstrom S. Maternity care in developing countries. In: Lawson BL, Harrison KA, Bergstrom S, eds. A Report. London: RCOG Press; 2001.

17. World Health Organization. Managing Complications in pregnancy and child birth. In: WHO, eds. Integrated Management of Pregnancy and Childbirth (IMPAC). Geneva: WHO; 2003.

18. David C. Lubansa (UNZA). A study of adequacy of informed consent for caesarean section at the university teaching Hospital, Lusaka, Zambia. Zambia: The University of Zambia. School of Medicine; 2010: 1-38. Available at: http://dspace.unza.zm:8080/xmlui/bitstream/handle/1 23456789/1448/Lubansad0001.PDF?sequence=1.

DOI: $10.18203 / 2320-1770 . i j r \operatorname{cog} 20150091$

Cite this article as: Latika, Nanda S, Duhan N, Malik R. Study of adequacy of informed consent in caesarean section in a tertiary care, teaching and research institute of Northern India. Int J Reprod Contracept Obstet Gynecol 2015;4:780-4. 